\begin{tabular}{|c|c|c|c|}
\hline \multirow{3}{*}{$\begin{array}{r}\text { Case Reports in } \\
\text { Gastroenterology }\end{array}$} & \multirow{2}{*}{\multicolumn{2}{|c|}{ Case Rep Gastroenterol 2020;14:286-290 }} & \multirow[b]{3}{*}{$\begin{array}{l}\text { Karger } \\
\text { Open'access }\end{array}$} \\
\hline & & & \\
\hline & $\begin{array}{l}\text { DOI: } 10.1159 / 000507611 \\
\text { Published online: May 13, } 2020\end{array}$ & $\begin{array}{l}\text { ( } 2020 \text { The Author(s) } \\
\text { Published by S. Karger AG, Basel } \\
\text { www.karger.com/crg }\end{array}$ & \\
\hline & $\begin{array}{l}\text { This article is licensed under } \\
\text { International License (CC BY-N } \\
\text { Usage and distribution for comm }\end{array}$ & $\begin{array}{l}\text { nons Attribution-NonCommercial } \\
\text { ger.com/Services/OpenAccessLice } \\
\text { uires written permission. }\end{array}$ & \\
\hline
\end{tabular}

\title{
Sigmoid Volvulus with Widespread Bowel Ischemia after Endoscopic Reduction Successfully Treated with Elective Laparoscopic Surgery
}

\author{
Koji Yasuda Shoji Oura Nozomi Kashu Hiroyuki Yoshitake \\ Tomoya Takami Hiroshi Shintani Naoki Kataoka \\ Tomoyuki Yamaguchi Shinichiro Makimoto \\ Department of Surgery, Kishiwada Tokushukai Hospital, Kishiwada, Japan
}

\section{Keywords}

Conservative treatment · Elective laparoscopic surgery · Sigmoid volvulus · Widespread ischemia

\begin{abstract}
An 87-year-old man complaining of abdominal distention was referred to our hospital. Plain radiograph and enhanced computed tomography $(\mathrm{CT})$ showed a dilated sigmoid colon with a coffee bean sign, leading to the diagnosis of sigmoid volvulus. Based on symptoms and the $\mathrm{CT}$ and laboratory test findings, we initially treated the patient with endoscopic reduction, resulting in successful reduction of the sigmoid volvulus with widespread presumed mucosal ischemia. Due both to the lack of emerging symptoms suggesting colon perforation and to the laboratory test findings after endoscopic reduction, we treated the patient without further urgent surgical intervention. Two months later, the patient underwent successful elective laparoscopic surgery with a redundant sigmoid colon resection and a functional end-to-end anastomosis. He has been well without any events for 20 months. Conservative treatment with careful observation should be taken into consideration in the treatment of sigmoid volvulus with mild to moderate ischemia after endoscopic reduction.

(C) 2020 The Author(s)

Published by S. Karger AG, Basel
\end{abstract}


Yasuda et al.: Sigmoid Volvulus with Widespread Ischemia Successfully Treated with Elective Surgery

\section{Introduction}

Various malignant diseases can cause large bowel obstruction. Especially, rectosigmoid, rectal, and anal malignancies tend to cause colon obstruction due to their smaller luminal sizes [1]. Noncolonic malignancies such as ovarian and pancreatic cancer can also cause colonic obstruction despite their low incidence rates compared with those of colonic malignancies [2].

Similarly, various benign diseases can cause colon obstruction functionally or mechanically. Of these, colon volvulus is the leading cause of colon obstruction and is common in the cecum and sigmoid colon [3]. Unlike cecal volvulus, sigmoid volvulus generally presents with abdominal pain, abdominal distention, and constipation/obstipation. In addition to these typical symptoms, plain radiograph [4] and computed tomography (CT) [5] facilitate the diagnosis of sigmoid volvulus.

Sigmoid volvulus generally needs immediate surgery on suspected/definitive perforation of the affected colon or primary endoscopic reduction followed by elective surgery due to its high rate of recurrence without further surgical intervention [6]. However, the presence of colonic mild to moderate ischemia after endoscopic reduction annoys the attending physician whether to urgently resect the affected colon or not.

We here report a case of sigmoid volvulus with widespread bowel ischemia after endoscopic reduction successfully treated with elective laparoscopic surgery under careful observation.

\section{Case Report}

An 87-year-old Japanese man complaining of abdominal distention was referred to our hospital. He had been surgically treated for early colon cancer and abdominal aortic aneurysm and nonsurgically for sigmoid colon volvulus. After being aware of insidiously presenting abdominal distention, the patient had failed to defecate for $12 \mathrm{~h}$ due to lack of intestinal peristalsis. He had no fever and complained of neither chills nor abdominal pain. Blood tests showed a mild inflammatory response and normal CPK level: white blood cells 10,200/ $\mu \mathrm{L}, \mathrm{C}$-reactive protein $0.183 \mathrm{mg} / \mathrm{dL}$, and CPK $89 \mathrm{U} / \mathrm{L}$. Plain abdominal radiograph and enhanced CT showed a markedly dilated colon in the fashion of the so-called coffee bean sign (Fig. 1). Blood test and enhanced CT findings (Fig. 2) led to the diagnosis of sigmoid volvulus without colon necrosis. The patient underwent initial and careful endoscopic reduction (Fig. 3a), leading to the successful reduction of the sigmoid volvulus followed by the improvement of abdominal distention. Although pretreatment assessment was sigmoid volvulus without colon necrosis, postreduction endoscopy showed widespread presumed mucosal ischemia (Fig. 3b). Considerable spread of the affected mucosa made it difficult for us to rule out the presence of transmural ischemia, which could lead to the necrosis of the sigmoid colon followed by peritonitis. However, we judged that the patient lacked the definitive evidence of necrosis of the detorsed sigmoid colon and decided to follow the patient with infusion, nil per os, and antibiotics administration under careful observation. Due both to no relapse of the abdominal symptoms and to the lack of increasing inflammatory response judged by laboratory tests, the patient started to take a meal on the 5th day and was discharged on the 9 th day after endoscopic reduction of the sigmoid volvulus. Two months later, i.e., after full recovery of his physical condition, the patient received endoscopic surgery with a $20-\mathrm{cm}$ resection of the redundant sigmoid colon and a functional end-to-end anastomosis as an elective surgery to prevent further recurrence. 


\section{Case Reports in Gastroenterology}

Case Rep Gastroenterol 2020;14:286-290

DOI: $10.1159 / 000507611$

(c) 2020 The Author(s). Published by S. Karger AG, Basel www.karger.com/crg

Yasuda et al.: Sigmoid Volvulus with Widespread Ischemia Successfully Treated with Elective Surgery

He recovered uneventfully and was discharged on the 8th day after the operation. He has been well without any events for 20 months.

\section{Discussion}

The initial step to diagnosing sigmoid volvulus is imaging diagnosis mainly with plain radiograph and CT. Thereafter, colonoscopy is generally done to further confirm the diagnosis and try to endoscopically detorse the sigmoid volvulus, if applicable. When endoscopic reduction is impossible, the disorder unquestionably needs an emergent operation due to the dismal prognosis of the sigmoid volvulus with perforation and peritonitis [7]. The attending physician, however, worries about the judgment either to follow or to emergently operate the patient when the sigmoid colon shows some ischemic changes after endoscopic reduction.

Compared with the stomach and small intestine, the colon often suffers from ischemia due to the presence of watershed areas between the major vessels: superior mesenteric artery, inferior mesenteric artery, and systemic circulation. In addition to the splenic flexure, the rectosigmoid junction is prone to ischemia, making the attending physician more anxious for the presence of colonic ischemia after endoscopic reduction of the sigmoid volvulus. Intramucosal $\mathrm{pH}$ measurement has been reported to be useful in predicting and managing the sigmoid colon with some ischemia after aortic operation [8]. Intramucosal $\mathrm{pH}$ measurement, however, is impractical in most medical facilities due to the lack of device to exactly measure the $\mathrm{pH}$ of the colon.

The guideline [9] says that endoscopic reduction should be performed when the laboratory tests do not indicate colon necrosis. In this case, we initially detorsed the sigmoid volvulus endoscopically and, even after the confirmation of widespread ischemia of the sigmoid colon, carefully followed the patient due both to the lack of emerging symptoms suggesting colon necrosis and to the laboratory test findings. Unlike cecal volvulus, easier endoscopic accessibility to the sigmoid colon further encouraged us to follow the patient conservatively with the intent of aiming for elective surgery.

Elective surgery after adequate bowel preparation enabled us to treat the patient with laparoscopic surgery, resulting in an uneventful postoperative course. Application of elective endoscopic surgery to the sigmoid volvulus has considerable debate, but has provided great benefit to this elderly patient with minimal damage. Despite the presence of prior surgeries in this case, we judged that laparoscopic surgery could be applicable because serial CTs provided the information about the adhesion among the sigmoid colon, small intestine, and peritoneum. When performed by a skilled team with full laparoscopic surgical expertise, elective laparoscopic surgery after successful endoscopic reduction should play an important role, especially in the treatment of elderly patients with sigmoid volvulus and various comorbidities such as cardiovascular and psychiatric disease.

In conclusion, conservative treatment with careful observation should be taken into consideration in the treatment of sigmoid volvulus with mild to moderate ischemia after endoscopic reduction. Elective laparoscopic surgery of the endoscopically detorsed sigmoid volvulus is a feasible alternative to conventional open surgery. 
Yasuda et al.: Sigmoid Volvulus with Widespread Ischemia Successfully Treated with Elective Surgery

\section{Statement of Ethics}

We have reported this case in compliance with the Declaration of Helsinki. Informed written consent was obtained from the patient for publication of the clinical data.

\section{Disclosure Statement}

The authors have no conflicts of interest to declare.

\section{Funding Sources}

No funding was received for this research.

\section{Author Contributions}

K. Yasuda contributed the design of the report. S. Oura and S. Makimoto drafted the manuscript. N. Kashu, H. Yoshitake, T. Takami, and H. Shintani, collected the data. N. Kataoka and T. Yamaguchi revised the manuscript. All authors read and approved the final version of the manuscript.

\section{References}

1 Aslar AK, Ozdemir S, Mahmoudi H, Kuzu MA. Analysis of 230 cases of emergent surgery for obstructing colon cancer - lessons learned. J Gastrointest Surg. 2011 Jan;15(1):110-9.

2 Buechter KJ, Boustany C, Caillouette R, Cohn I Jr. Surgical management of the acutely obstructed colon. A review of 127 cases. Am J Surg. 1988 Sep;156(3 Pt 1):163-8.

3 Halabi WJ, Jafari MD, Kang CY, Nguyen VQ, Carmichael JC, Mills S, et al. Colonic volvulus in the United States: trends, outcomes, and predictors of mortality. Ann Surg. 2014 Feb;259(2):293-301.

4 Hiltunen KM, Syrjä H, Matikainen M. Colonic volvulus. Diagnosis and results of treatment in 82 patients. Eur J Surg. 1992 Nov-Dec;158(11-12):607-11.

5 Catalano 0. Computed tomographic appearance of sigmoid volvulus. Abdom Imaging. 1996 Jul-Aug;21(4): 314-7.

6 Atamanalp SS. Treatment of sigmoid volvulus: a single-center experience of 952 patients over 46.5 years. Tech Coloproctol. 2013 Oct;17(5):561-9.

7 Kuzu MA, Aslar AK, Soran A, Polat A, Topcu O, Hengirmen S. Emergent resection for acute sigmoid volvulus: results of 106 consecutive cases. Dis Colon Rectum. 2002 Aug;45(8):1085-90.

8 Fiddian-Green RG, Amelin PM, Herrmann JB, Arous E, Cutler BS, Schiedler M, et al. Prediction of the development of sigmoid ischemia on the day of aortic operations. Indirect measurements of intramural $\mathrm{pH}$ in the colon. Arch Surg. 1986 Jun;121(6):654-60.

9 Vogel JD, Feingold DL, Stewart DB, Turner JS, Boutros M, Chun J, et al. Clinical Practice Guidelines for Colon Volvulus and Acute Colonic Pseudo-Obstruction. Dis Colon Rectum. 2016 Jul;59(7):589-600. 
Yasuda et al.: Sigmoid Volvulus with Widespread Ischemia Successfully Treated with Elective Surgery

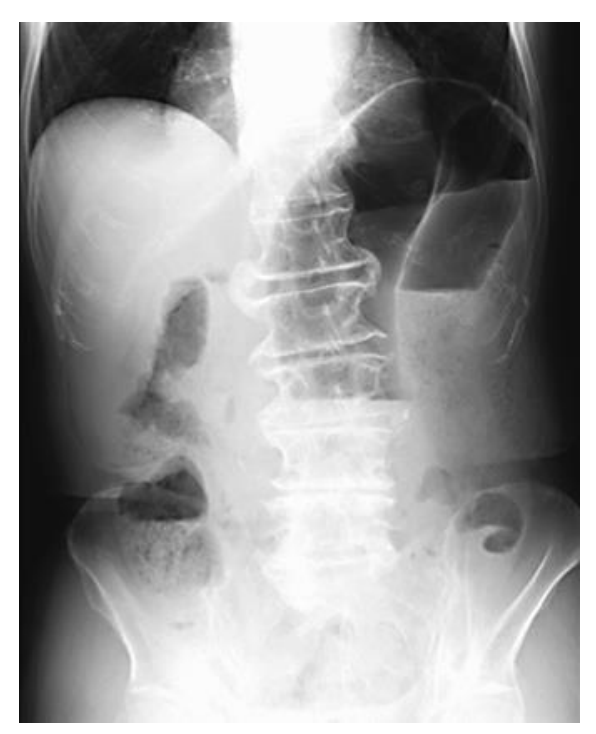

Fig. 1. Plain abdominal radiograph showing a dilated sigmoid colon reaching up to the left diaphragm in the fashion of the so-called coffee bean sign.

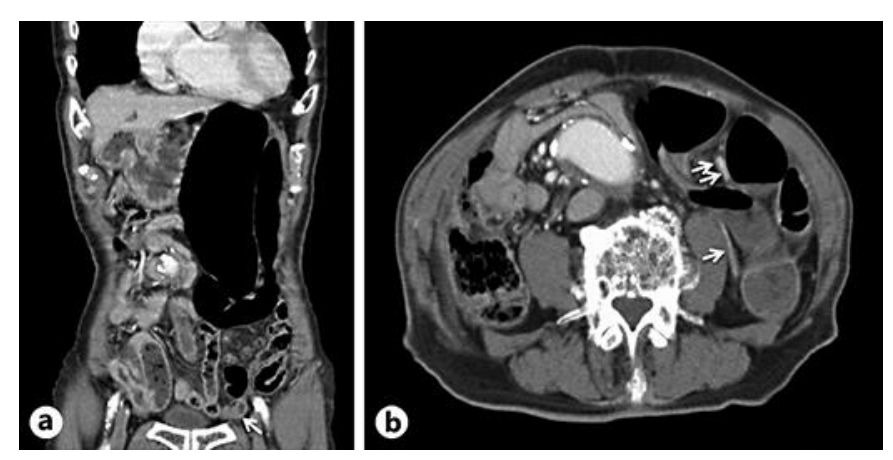

Fig. 2. Enhanced CT of the abdomen. a Coronal view of the enhanced CT showed a dilated sigmoid colon and the absence of rectal gas (arrow). $\mathbf{b}$ Axial view of the enhanced CT showed a dilated colon and patent mesenteric (arrow) and marginal (arrows) arteries. CT, computed tomography.
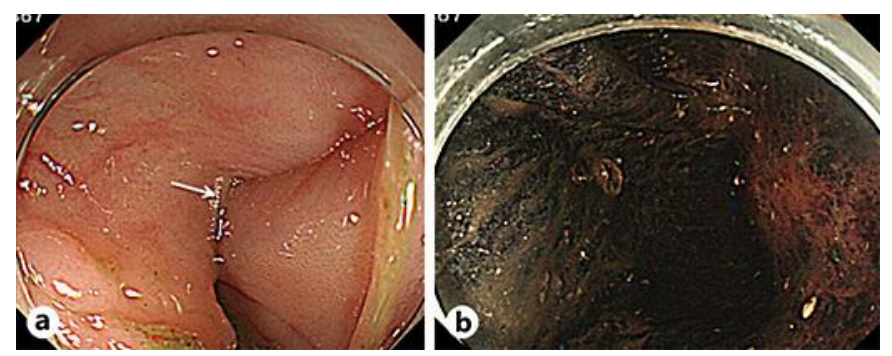

Fig. 3. Colonoscopy showed a twisted portion (arrow) of the sigmoid colon (a) and widespread presumed mucosal ischemia after endoscopic reduction (b). 